\title{
TÉCNICAS E OFICINAS DE PRODUÇÃO DE COSMÉTICOS E, APRENDIZAGEM E INSERÇÃO SOCIAL NO ENSINO MÉDIO: FUNÇÕES ORGÂNICAS E EMPODERAMENTO FEMININO
}

\section{TECHNIQUES AND OFFICES OF COSMETICS PRODUCTION AND LEARNING AND SOCIAL INSERTION IN MIDDLE SCHOOL: ORGANIC FUNCTIONS AND FEMALE EMPOWERMENT}

\author{
Joedna Sabino de Souza ${ }^{1}$; Mayzza Márcia Araújo do Nascimento²; Geovana Camargo \\ Vargas $^{3}$
}

\section{INTRODUÇÃO}

Dentro de um contexto educacional, as ferramentas metodológicas auxiliam na Aprendizagem de uma forma ampla e fazem os estudantes aprenderem como conciliar os conteúdos vistos dentro de sala sendo inseridos em seus cotidianos, tentando de alguma forma exemplificar os conteúdos abordados em Química. Uma ferramenta importante, que atualmente vem ganhando destaque entre os professores e os alunos é a experimentação. Dentro das aulas de Química a sua aplicação é de suma importância, pois ela, conciliada com base teórica e experimental, faz os conteúdos se aproximarem da compreensão dos alunos. Sabe-se que a Química é dividida entre diversos temas e conteúdo, porém entre um dos mais importantes é o estudo da Química Orgânica. A Química Orgânica possui aspectos que são sempre interligados com a experimentação e uma das formas de aplicá-la dentro do laboratório é estudar as suas funções, adquirindo técnicas facilitadoras na compreensão contextualizada.

Uma saída para que se sejam efetuadas aulas práticas que facilitem a compreensão do conteúdo de funções orgânicas, é aplicá-las através de oficinas na área de cosmético. Devido à utilização de compostos orgânicos em sua fabricação. Tronando importante para que o estudo teórico, que ganhe se reforça em sala, é possível assim, por meio da prática a visualização da de como se aplica em cada experimento as teorias, observando como é o comportamento de cada reação. Além de promover amplo conhecimento sobre o conteúdo, os estudantes podem ir além da sala de aula e fornecer a oficina na forma de extensão, para outros públicos. Assim, também pode ser forma

\footnotetext{
${ }^{1}$ Professora, Governo do Estado da Paraíba, eddnasouza@gmail.com

2 Licenciatura em Química, IFPB mayzzaaraujo.quim@hotmail.com

${ }^{3}$ Doutora em Psicologia Cognitiva,IFPB, geovanacv@gmail.com
} 
o senso crítico e humanitário dos mesmos. Qualificados não somente para o aprendizado dos conteúdos, mas para uma visão de como melhorar a perspectiva do seu cotidiano.

A oficina para os estudantes pode ser reaplicada por eles dentro da própria escola e fora dela, aproximando assim um segundo público alvo as mulheres, que vivem na comunidade. Uma das mais preocupantes atualmente e que possui pouco apoio e amparo é a violência doméstica, que afeta mundialmente mulheres de classes sociais distintas, porém a maioria dos casos ocorre com mulheres de baixa rende e que possuem uma dependência financeira com o agressor. A importância de uma oficina voltada para esse público é fazer com que essas mulheres sejam qualificadas, para exercer uma profissão que a torne independente financeiramente, gerando assim a sua própria renda. Importante aplicar em conjunto com os estudantes, pois dessa forma eles conseguem entender a importância do aprendizado teórico e prático da Química.

\section{FUNDAMENTAÇÃO TEÓRICA}

A situação atual da Educação no Brasil nos proporciona uma reflexão quanto à prática docente, em que se faz necessária a busca por práticas educativas que tentem diminuir a barreira encontrada no aprendizado dos discentes. Dentro dessas dificuldades, muitas ainda são limitadas por uma ideologia que só remete ao teórico. É importante o reconhecimento da teoria e leitura dos termos científicos, porém deve-se analisar a prática como uma linha que se coaduna com a teoria, em sua visualização. É notório o quanto os alunos conseguem sair de uma aula experimental, com mais entendimento dos conhecimentos teóricos vistos em sala de aula.

Portanto, à medida que se planejam experimentos com os quais é possível estreitar o elo entre motivação e aprendizagem, espera-se que o envolvimento dos alunos seja mais vívido e, com isso, acarrete evoluções em termos conceituais (FRANCISCO JR et al., 2008, p.34).

Há duas possibilidades que podem auxiliar na relação entre o conhecimento do professor e quanto o estudante está disposto a aprender. A primeira é a forma como as aulas são elaboradas. Para a disciplina de Química a contextualização dos conteúdos é importante para os estudantes, pois discutir situações que envolvem o cotidiano, assim como utilizar de recursos midiáticos, por mais que seja no contexto teórico, o importante é propiciar o entendimento aos discentes quanto ao conteúdo abordado na aula, além de enfatizar o quanto aquele assunto é essencial para o seu aprendizado. Conforme Zuliane (2006 apud FERREIRA. et al., 2010, p. 
101-102) "a investigação a partir de fatos cotidianos é um fator essencial no processo de evolução conceitual dos alunos".

A segunda refere-se à aplicação de aulas experimentais que consigam complementar as aulas teóricas. Para elaboração do plano é preciso que sejam aplicadas às ferramentas que pretendem nortear o trabalho do professor. Por isso, na química a estratégia mais utilizada e que possui um efeito bastante positivo é a experimentação. De acordo com Pazinato et al.(2012, p.21) “A experimentação no ensino de química desperta um forte interesse nos diversos níveis de escolarização, pois os alunos costumam atribuir à experimentação um caráter motivador, lúdico, essencialmente vinculado aos sentidos". Para o estudante é importante garantir a visualização nas práticas em conjunto com as teorias de sala. Uma vertente do aprendizado de orgânica são suas funções dentre as quais a maioria pode se relacionar com a contextualização da fabricação de cosmético.

A utilização da oficina de cosmético pode ser trabalhada para exemplificar a forma de diversas técnicas dentro do laboratório, como destilação, separação de compostos orgânicos e, principalmente, a utilização das funções orgânicas dentro do contexto social. Assim, de acordo com Marcondes (2008, p. 3) "Os conteúdos a serem tratados em sala de aula devem ter uma significação humana e social, de maneira a interessar e provocar o aluno e permitir uma leitura mais crítica do mundo físico e social. " Através da oficina os estudantes podem adquirir a capacidade de desenvolver essas técnicas fora da sala de aula, trabalhar com a extensão do conhecimento, levando-o em forma da própria ferramenta oficina, para lugares como, por exemplo, ONGs, outras escolas, até mesmo promover de forma competente dentro da sua própria instituição de ensino. Deste modo, garante-se o aprendizado sobre o conteúdo e a capacidade de relacionar as aulas dentro da sala de aula com o contexto de vivência.

Ainda com a oficina é possível trabalhar a diferença de gênero dentro da sala de aula, por ser um tema que desperta o interesse maior feminino, fazendo a aplicação de forma extensiva para as mulheres que precisam gerar renda ou que sofreram alguma forma de violência doméstica, por exemplo. É importante fazer com que as estudantes consigam entender esse lado social da aprendizagem, promovendo ferramentas para desenvolver conhecimentos sobre igualdade de gênero, ética e empoderamento feminino.

A diferença de gênero destaca-se dentro ou fora do nosso cotidiano, é de suma necessidade ações que fujam da caracterização da desigualdade enfrentada por diversas mulheres. A dependência de muitas, a falta de formação e a necessidade de renda que a maioria possui, exercem um limite em suas decisões, como combater e enfrentar o machismo e a violência doméstica em suas vidas. Infelizmente muitas servem como exemplo e entram na 
estatística dessa dependência e desse ciclo de violência, que permeia a nossa sociedade. De acordo com a pesquisa da Sociedade Mundial de Vitimologia da Holanda, sobre violência doméstica contra mulher, citado em Oliveira et al.(2006)

23\% das mulheres brasileiras estão sujeitas à violência doméstica; a cada minuto, uma mulher é agredida em seu próprio lar por uma pessoa com quem mantém relação de afeto; as estatísticas disponíveis e os registros nas delegacias especializadas de crimes contra a mulher demonstram que $70 \%$ dos casos acontecem dentro de casa e que o agressor é o próprio marido ou companheiro.

A violência presente dentro casa é a que mais mata atualmente (olha no mapa da violência) e a que mais limita a mulher a enxergar a sua capacidade de ir além. Por isso, tornamse necessárias políticas públicas voltadas para incentivar a denúncia e fazer com que essas mulheres busquem uma fonte de renda quebrando, assim, esse ciclo de violência. É possível encontrar iniciativas que quebrem esse histórico na sociedade, práticas que estimulem o crescimento social feminino e incentivem o empoderamento, não só no dentro do âmbito familiar, mas em todo o seu contexto social. A oficina de cosméticos busca além de aprimorar da capacidade de interação dessas mulheres com a sociedade, buscar uma ferramenta para a geração de renda, vislumbrando crescimento profissional feminino e fazendo com que essas mulheres sejam exemplo para outras. É possível associar o crescimento feminino através dessa ferramenta, pois a mesma adere conhecimentos do cotidiano e se insere em uma perspectiva econômica e social.

\section{METODOLOGIA}

O trabalho tem cunho participante, isto é, o pesquisador deve partir da realidade da vida cotidiana dos participantes, compartilhando as vivências dos pesquisados mediante a observação dos fenômenos, participando, sistematicamente e permanentemente, ao longo do tempo da pesquisa e das suas atividades (MARCONI; LAKATOS, 2010). Quanto à natureza da abordagem.

Para o planejamento dessas práxis foi analisado o conteúdo programático a ser aplicado na turma, seguindo o Plano de Ensino da escola. As aulas foram elaboradas tendo por base o uso de ferramentas metodológicas que oportunizassem uma aprendizagem real e significativa. A aplicação da atividade deu-se durante 21 aulas, com duração de 50 (cinquenta) minutos cada, com exceção da aula experimental, contemplando o conteúdo Funções Orgânicas. De maneira contextualizada, o conteúdo foi apresentado através das substâncias químicas utilizadas na 
fabricação de cosméticos. Além disso, houve discussões sobre empoderamento feminino, desigualdade de gênero, trazendo para o contexto as mulheres participantes. Para a execução das aulas teve-se como proposta permanente a exposição dialogada dos contextos químicos. Em algumas aulas foi utilizado o recurso midiático (slides) para exposição de imagens e também apresentação de vídeos. Além disso, utilizou-se da oficina experimental de cosméticos explorando teoria e prática, concomitantemente. Por não possuir um laboratório próprio na escola, a oficina experimental foi realizada no Laboratório de Química do IFPB - campus João Pessoa. Nessa oficina, os discentes tiveram a oportunidade de conhecer um laboratório de Química, assim como instrumentos e técnicas utilizadas em laboratório.

\section{RESULTADOS E DISCUSSÕES}

Foi possível analisar que, dentro do contexto dos estudantes, foi essencial a utilização da contextualização Química e de questões sociais, na associação do cotidiano com as práticas experimentais. Além da importância de uma escola estruturada para atender as principais necessidades na educação, com a disponibilização de um laboratório para auxiliar nas aulas teóricas. A contextualização em sala, a busca por induzir os estudantes a pensarem com as possíveis possibilidades que há no próprio cotidiano, facilitam no entendimento que a Química Orgânica e suas funções estão em todos os lugares e para entender é necessário somente ampliar sua capacidade de olhar além do mundo em sala de aula. A demais, expressaram a importância de buscar temas que possam estimular o estudo além da Química, a exemplo do Empoderamento feminino. A participação de todos na aplicação de cada etapa foi essencial, tanto nas aulas de Química como nas aulas com temas sociais enquadrando-se ao tema de empoderamento feminino e o projeto. Devido à grande representação que existe dentro do assunto e em geral nas disciplinas de Ciências exatas, a revisão dentro das aulas das funções orgânicas auxiliaram bastante para o nivelamento da turma. Os estudantes se ajudaram nessa etapa de reconhecimento das funções.

\section{CONCLUSÕES}

Finalmente, a utilização de uma ferramenta que se insira na realidade do estudante e a problematize mostra-se necessária na formação acadêmica. É desafiador trazer temas para que a maioria dos estudantes associe à teoria, já que pouco se enxerga a prática dentro de seus cotidianos. Por isso, diferenciar com uma aplicação social e que se encontra presente no dia a dia dos mesmos facilita a aprendizagem e a forma que procuram aprender, associando sempre com práticas mais presentes em suas vidas. Com isso, o docente tem que ampliar sua capacidade 
de ensinar, observando a necessidade que os estudantes possuem e como a sua ferramenta metodológica vai efetuar e despertar o crescimento desse estudante. Espera-se, assim, tornar a Química uma disciplina de fácil compreensão e essencial na formação humana dos indivíduos.

\section{REFERÊNCIAS}

DE OLIVEIRA, Celin Camilo. DA FONSECA, Rosa Maria Godoy Serpa. Práticas dos profissionais das equipes de saúde da família voltadas para as mulheres em situação de violência sexual. Revista da escola de Enfermagem da USP, v, 41 n. 4, p 605 - 612, 2007.

FERREIRA, Luiz Henrique; HARTWIG, Dácio Rodney; OLIVEIRA, Ricardo Castro de. Ensino experimental de química: uma abordagem investigativa contextualizada. Química Nova na Escola, v. 32, n. 2, p. 101-106, 2010.

FRANCISCO JR, Wilmo E; FERREIRA, Luiz Henrique; HARTWIG, Dácio Rodney. Experimentação problematizadora: fundamentos teóricos e práticos para a aplicação em salas de aula de ciências. Química Nova na Escola, v. 30, n. 4, p. 34-41, 2008.

MARCONI, M. A.; LAKATOS, E. M. Fundamentos de metodologia científica. 7a ed. São Paulo: Atlas, 201

MARCONDES, Maria Eunice Ribeiro. "Proposições metodológica para o ensino de Química: Oficina temática para aprendizagem da ciência e o desenvolvimento da cidadania. Extensão, Uberlândia, v, 7, n. 1. 67-77, 2008. 